\title{
Genetics of arsenic tolerance in Agrostis capillaris $\mathrm{L}$.
}

\author{
A. J. WATKINS* \& M. R. MACNAIR \\ Department of Biological Sciences, Hatherly Laboratories, University of Exeter, Prince of Wales Road EX4 4PS, U.K.
}

\begin{abstract}
The genetic control of arsenic tolerance in Agrostis capillaris is examined by two experiments, one involving natural seed families collected from the wild and one based on the six basic generations from a cross between a tolerant plant and a non-tolerant plant. Arsenic tolerance is shown to be an inherited characteristic, the tolerant trait being dominant. Control by more than one gene locus is indicated by the data, although the number of loci involved appears to be small. The genetic architecture of this character allows for heritable variation in degree of tolerance among tolerant plants.
\end{abstract}

Keywords: Agrostis capillaris, arsenic tolerance, dominance, genetic control, modifier genes.

\section{Introduction}

For any adaptation to evolve by natural selection, there must be heritable variation for the character in question. The phenomenon of heavy-metal tolerance is firmly established in the literature as one of the best examples of local adaptation and microevolution (reviewed by Antonovics, Bradshaw \& Turner, 1971; Macnair, 1981, 1987a). However, while the difference between tolerant and non-tolerant races has, in many cases, been shown to be heritable, the genetic architecture of this difference has only been examined in a minority of studies (reviewed by Macnair, 1990). There are no previous reports on the inheritance of arsenic tolerance.

Although arsenic is not, strictly speaking, a heavy metal, it is convenient to consider it in this category in so far as plant evolutionary responses are concerned.

Porter \& Peterson (1977) showed that plants from populations of Agrostis capillaris L. (Syn. A. tenuis Sibth.), growing on abandoned arsenic mines in the Tamar valley (Devon, U.K.), had a higher degree of tolerance to arsenate toxicity than plants from nontoxic environments. Arsenic tolerance has also been found in Andropogon scoparius (Rocovich \& West, 1975), but in neither case has the difference between tolerant and non-tolerant types been shown to be heritable. The degree of arsenic tolerance varies even

*Current address: S.P.A.S., University of the South Pacific, Box 1168, Suva, Fiji. between tolerant plants according to the data of Rocovich \& West (1975), a variation which appears to correlate with the arsenic toxicity of the soil from which each plant was collected (Macnair 1981). Similar correlations were found in arsenic-tolerant populations of A. capillaris from mine sites in Devon (Macnair, $1987 \mathrm{~b})$. This implies the existence of a set of selection pressures, adapting a plant to its micro-environnment, capable of working on a scale that is finer grained than that of mine/non-mine. This suggestion depends on the assumption that the variation in degree of tolerance is heritable.

The following questions therefore arise: is arsenic tolerance heritable and, if so, does the genetic architecture of the character allow for a heritable variation in degree of tolerance? Perhaps the single most important factor is the number of genes involved in the expression of the character. Dominance is also important in the sense that a single gene locus with two alleles can show two or three phenotype classes depending on the dominance relationship of the two alleles.

In outbreeding species, it is usually assumed that individuals will not necessarily be homozygous with respect to the gene loci in question and genetic models are, therefore, correspondingly complex.

If individuals can be considered to be homozygous, at least over the loci under examination, this allows considerable simplification. In this work, therefore, consideration has been given to locating parents homozygous for tolerance characters for use in the breeding experiment. 
This paper presents the results of two experiments investigating the genetic control of arsenic tolerance in A. capillaris.

\section{Materials and methods}

\section{Experiment 1}

Twenty natural seed families of $A$. capillaris, each consisting of the seed from one seed head, were collected at random from a $10 \times 10 \mathrm{~m}$ plot of Ramsley mine in Devon (SX 650930). Care was taken not to sample any one clone twice. This mine site is contaminated with both arsenic $\left(475 \pm 62 \mu \mathrm{g} \mathrm{g}^{-1}\right)$ and copper (1781 $\left.\pm 169 \mu \mathrm{g} \mathrm{g}^{-1}\right)$. From each family, six randomly selected representatives were grown on non-toxic soils under glasshouse conditions and tested for tolerance using the parallel root growth method modified from Jowett (1959) and McNeilly (1968). The toxic solution contained $6 \mathrm{mg} \mathrm{l}^{-1}$ of arsenic as sodium arsenate; both control and toxic solutions contained $0.5 \mathrm{~g} \mathrm{l}^{-1}$ calcium nitrate. Tillers remained in control solution for $24 \mathrm{~h}$ after cutting, then were transferred to the experimental blocks, being suspended in 10-litre plastic trays and supported in narrow perspex tubes. Solutions were changed three times per week. The roots were permitted to grow for 14 days in a growth cabinet under constant illumination by cold white fluorescent tubes and incandescent bulbs. Temperature was maintained at $23^{\circ} \mathrm{C} \pm 1{ }^{\circ} \mathrm{C}$ and humidity at $90 \pm 6$ per cent. Root length was measured only once, at the end of the experiment, to minimize root damage. From each plant, five replicate tillers were tested in each of the two solutions; for analysis, the longest root overall of the five replicates was used.

The control root lengths showed no significant differences between families, thus the actual root lengths in toxic solution, rather than tolerance indices, have been used in subsequent analyses. Wilkins (1978) and Macnair (1990) argue that, where possible, root length should be used in preference to tolerance index.

On examining the results, it became apparent that plants could be largely classified as tolerant $(T)$ and non-tolerant (NT), with very little overlap between these two classes (see Fig. 1a). The results were therefore analysed in two ways:

(a) using heterogeneity of the T:NT ratios between families to determine whether arsenic tolerance per se is heritable;

(b) using an analysis of variance, after eliminating all families that segregated non-tolerant individuals, to determine if degree of tolerance among tolerant plants is heritable.

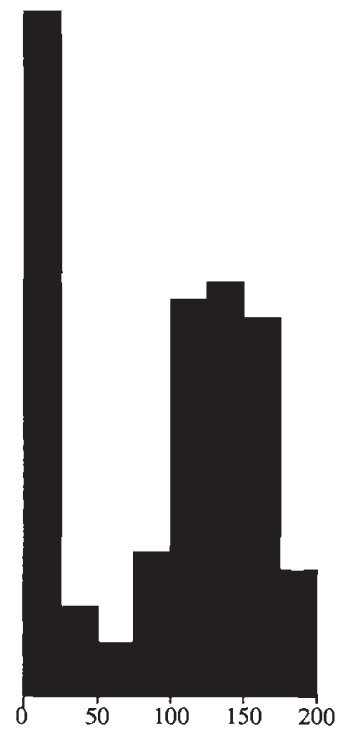

c.

b.

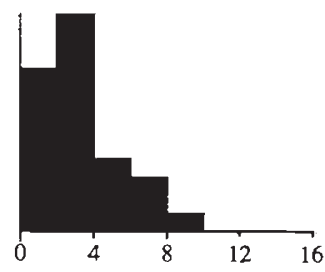

Fig. 1 Distributions of root lengths (in $\mathrm{mm}$ ) in natural seed offspring. (a) All data (119 offspring). (b) Expanded scale to show NT group. (c) Expanded scale to show NT, intermediate and start of T groups. Arrows indicate the points of overlap between curves.

\section{Experiment 2}

\section{Provenance and crossing programme}

Working on the assumption that a reasonably high proportion of mine plants will be homozygous for tolerance (Macnair, 1979), several plants of $A$. capillaris were collected as tillers from the central areas of the Gawton United mine in Devon (SX 452688). These were designated the $P_{1}$ generation and each one was crossed with a different non-tolerant plant (the $\mathrm{P}_{2}$ generation) to produce an $F_{1}$. The non-tolerant material was taken from an edaphically similar but non-toxic site at Woodbury Common, Devon (SY 031872). Cross pollination was achieved by growing the two parents on either side of a divided pot and sealing the flowering heads in a glassine bag. The same method was used to backcross the $F_{1}$ to the parents, $P_{1}$ and $P_{2}$, to give the $B_{1}$ and $B_{2}$ generations, respectively. Five $F_{1}$ plants were intercrossed to give an $F_{2}$ generation, by enclosing them in a chamber into which filtered air was pumped to maintain a positive pressure. Seed repre- 
senting the $P_{1}$ and $P_{2}$ generations was obtained by intercrossing individual plants within these two generations.

No selfing was expected to occur because $A$. capillaris is an obligate outbreeder. Flowering heads were bagged individually on five plants; none of these set any seed. Representative seed of each generation was produced in the same year to avoid any effects of seed ageing.

This paper is concerned with only one of these crosses because, in all but one case, the parents were demonstrably not homozygous for the loci in question. Crosses were eliminated on these grounds if either the $F_{1}$ variance was significantly higher than that of one or both parents or the $F_{2}$ family means differed significantly between maternal parents. It is, of course, impossible to be certain that the parents of the remaining cross were homozygous, but there is no evidence that they were not.

\section{Tolerance testing}

The seedlings were transferred to individual pots of arsenic-contaminated soil on the day after germination and raised in a randomized array in a greenhouse. Tolerance was measured as plant height after 60 days. No plants had produced more than one tiller at this stage. This technique confounds tolerance with growth rate, but may be justified as follows.

(a) Height on toxic soil correlates strongly with tolerance index (Walley, Khan \& Bradshaw, 1974).

(b) Height variation in a segregating generation $\left(F_{2}\right)$ grown on toxic soil is very large compared to the height variation of this generation on non-toxic soil (see Fig. 2).

(c) The technique allows much larger numbers of individuals to be examined.

When using seedling height, a character that may be dependent on maternal input as seed capital, it is important to check for maternal effects. Most crosses were carried out reciprocally; there were no significant reciprocal differences in any crosses, therefore the results are pooled. In each generation, roughly equal numbers of seed were obtained from the reciprocal crosses. Unfortunately, reciprocal crosses do not exist for the most important generation, the $\mathrm{B}_{2}$. However, reciprocal $\mathrm{B}_{2}$ families from the crosses that were eliminated showed no reciprocal differences. The $F_{1}$ plants and the $P_{1}$ were tested for selfing and no selfing was detected. The $\mathrm{B}_{2}$ generation could not, therefore, consist of a mixture of seed of different provenance.

\section{Analysis}

The height data were rescaled by taking the cube root, as this transformation resulted in similar variances for
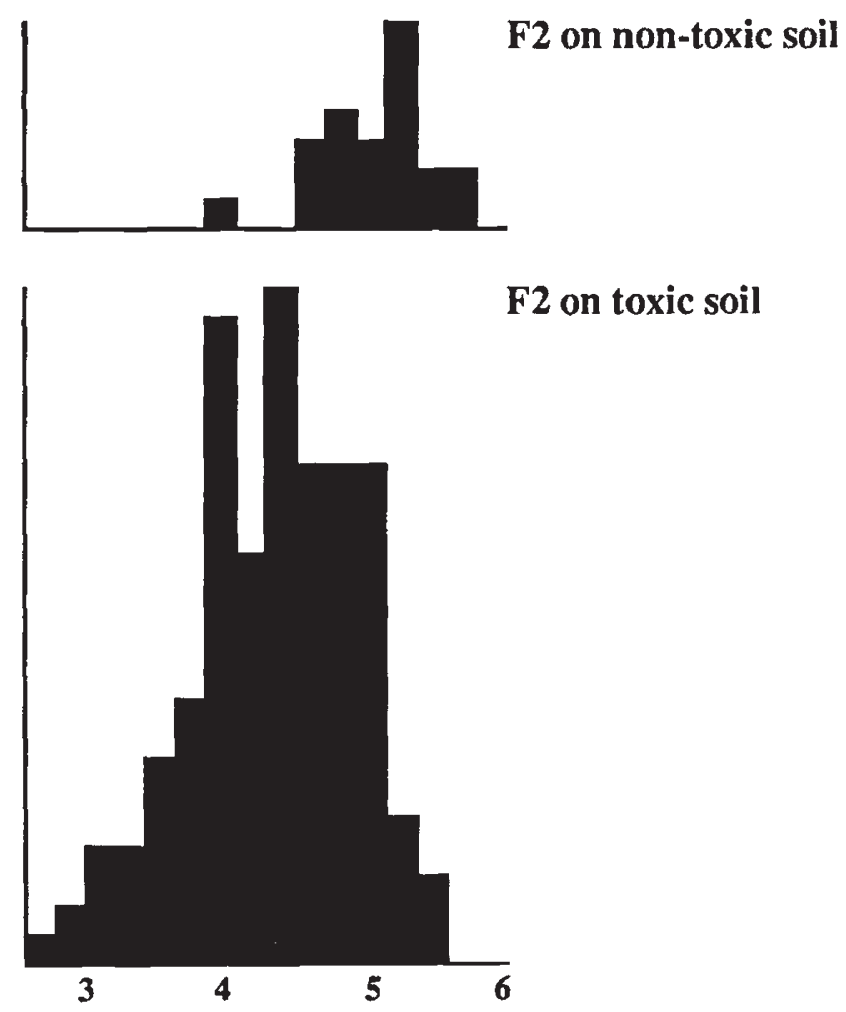

F2 on toxic soil

\section{Rep. 1 plant}

Fig. 2 Distribution of sizes of $\mathrm{F}_{2}$ plants grown on non-toxic and toxic soil, showing the greater variance on toxic soil. Size measured as the cube root of tiller height in millimetres.

the $P_{1}$ and $P_{2}$ generations, while normalizing the distributions of the non-segregating generations.

The joint scaling test of Cavalli (1952) was used to test the adequacy of the simple additive-dominance model. Non-allelic interactions were investigated using the formulae of Jinks \& Jones (1958) and a suitable model fitted by modification of the Cavalli method (Mather \& Jinks, 1971).

The segregating generations were examined for evidence of separation into classes that might indicate control by a small number of genes.

\section{Results}

\section{Experiment 1}

The histogram in Fig. 1a shows the segregation of root lengths into two classes, T and NT. Since there is some overlap between the two classes, the point of overlap was determined by iteratively fitting normal curves on each side of the crossover point. This analysis, in fact, located two points of overlap at $12 \mathrm{~mm}$ and $59 \mathrm{~mm}$, 
dividing the data into three curves, which can be seen by expanding the scale at the lower end of the histogram (Fig. 1b and c). This is probably an artefact, the central curve being composed of legitimate outliers from the outer two curves. About six outliers would be expected and eight actually occur. They have been included with $\mathrm{T}$ plants in subsequent analyses, but it should be noted that removing them from this group does not materially affect the outcome of the analyses. Thus, all plants with root lengths below the lower overlap value $(12 \mathrm{~mm})$ were classified as NT and all those above as $\mathrm{T}$.

The numbers of $\mathrm{T}$ and NT individuals are shown in Table 1 . The heterogeneity $\chi^{2}$ value is significant. Because the expected values in some cells of the heterogeneity table are small, the robustness of the test was checked by a randomization test. Tables were generated, containing $20 \times 2$ cells, and the cells filled with random integers, with the constraint that marginal totals remained the same as the original data. A total of 1000 tables were generated and the heterogeneity $\chi^{2}$ value computed for each. In only 20 of these was the observed $\chi^{2}$ value exceeded, confirming that families show significant heterogeneity.

This indicates that the families differ in T:NT ratio. If the families all have the same ratio, either the character is not heritable, or all the original plants had the

Table $1 \mathrm{~T}$ :NT ratios in the progeny of 20 natural seed families

\begin{tabular}{lrrr}
\hline Family & $n$ & $\mathrm{~T}$ & $\mathrm{NT}$ \\
\hline 1 & 5 & 4 & 1 \\
2 & 6 & 6 & 0 \\
3 & 6 & 3 & 3 \\
4 & 6 & 6 & 0 \\
5 & 6 & 5 & 1 \\
6 & 6 & 3 & 3 \\
7 & 6 & 3 & 3 \\
8 & 6 & 6 & 0 \\
9 & 6 & 5 & 1 \\
10 & 6 & 4 & 2 \\
11 & 6 & 4 & 2 \\
12 & 6 & 4 & 2 \\
13 & 6 & 2 & 4 \\
14 & 6 & 6 & 0 \\
15 & 6 & 5 & 1 \\
16 & 6 & 6 & 0 \\
17 & 6 & 5 & 1 \\
18 & 6 & 5 & 1 \\
19 & 6 & 2 & 4 \\
20 & 6 & 6 & 29 \\
& 119 & 90 & \\
\hline
\end{tabular}

Heterogeneity $\chi_{[19]}^{2}=31.7, P<0.05$. same genotype. If, however, the ratios differ significantly between families, the differences must be the result of differing parental genotypes. Thus, the character of tolerance can be assumed to be heritable.

Analysis of variance of root lengths within and between families (Table 2), including only families containing all $\mathrm{T}$ individuals, shows that there are significant differences between families, at the $P=0.05$ level. This indicates that there is, apparently, a heritable component in the degree of tolerance shown by tolerant plants although the probability value is not sufficiently high for this result to be considered unequivocal.

\section{Experiment 2}

The histograms in Fig. 2 demonstrate that the height variation in $F_{2}$ plants grown on toxic soil is much greater than that of $F_{2}$ plants grown on non-toxic soil. The latter reflects variation in overall growth rate, which will be confounded with the measurement of tolerance, in this experimental design. This variation (variance 0.129 ) is comparable with the variances of the non-segregating generations (Table 3), suggesting that this may be considered as a general error variance. The mean, variance and family size of each of the six generations are given in Table 3 and the Cavalli joint scaling test for the simple additive dominance model is shown in Table 4 . The model fails to fit, as shown by

Table 2 Analysis of variance table. Variation in degree of tolerance in all-tolerant families

\begin{tabular}{lrlll}
\hline Item & df & MS & $F$ & $P$ \\
\hline Between families & 5 & 3075 & 2.54 & 0.05 \\
Within families & 30 & 1212 & & \\
TOTAL & 35 & & & \\
\hline
\end{tabular}

$\mathrm{MS}=$ mean square.

Table 3 Summary statistics for tiller height (cube root transformation) for the first six generations of the selfing series

\begin{tabular}{lrll}
\hline Generation & $n$ & Mean & Variance \\
\hline $\mathrm{P}_{1}$ & 33 & 4.90 & 0.208 \\
$\mathrm{P}_{2}$ & 15 & 3.40 & 0.179 \\
$\mathrm{~F}_{1}$ & 59 & 5.04 & 0.186 \\
$\mathrm{~F}_{2}$ & 145 & 4.33 & 0.301 \\
$\mathrm{~B}_{1}$ & 81 & 4.82 & 0.270 \\
$\mathrm{~B}_{2}$ & 67 & 4.14 & 0.525 \\
\hline
\end{tabular}


Table 4 Cavalli joint scaling test using the additive and dominance parameters only

\begin{tabular}{lllll}
\hline Parameter & Estimate & Generation & $\begin{array}{l}\text { Observed } \\
\text { mean }\end{array}$ & $\begin{array}{l}\text { Expected } \\
\text { mean }\end{array}$ \\
\hline $\mathrm{m}$ & $3.973 \pm 0.053$ & $\mathrm{P}_{1}$ & 4.90 & 4.74 \\
{$[\mathrm{~d}]$} & $0.772 \pm 0.055$ & $\mathrm{P}_{2}$ & 3.40 & 3.20 \\
{$[\mathrm{~h}]$} & $0.930 \pm 0.085$ & $\mathrm{~F}_{1}$ & 5.04 & 4.90 \\
& & $\mathrm{~F}_{2}$ & 4.33 & 4.44 \\
$\chi_{[3]}^{2} 34.15$ & & $\mathrm{~B}_{1}$ & 4.82 & 4.82 \\
$P<0.001$ & & $\mathrm{~B}_{2}$ & 4.14 & 4.05 \\
\hline
\end{tabular}

the highly significant $\chi^{2}$ value. The presence of nonallelic interactions is shown in Table 5, where the estimate of $[i]$ is significantly different from zero, but the estimates of [i] and [l] are not. The symbol [i] represents a summation of the interactions between the additive properties of the genes for all loci involved. When the parameter [i] is included in the model (Table $6)$, the model fits.

The model indicates that arsenic tolerance is heritable, showing additive genetic variance, with the tolerant trait showing dominance. The degree of dominance is indicated by comparing the estimate of $[\mathrm{h}]$ with that of $[\mathrm{d}]+[\mathrm{i}]$, thus the dominance ratio is approximately 1 . The tolerant trait is, therefore, showing complete dominance. The presence of interactions between loci implies that there is more than one locus involved, although this could be an artefact of the data (see Discussion).

The variances cannot be partitioned into the additive and dominance portions of the heritable variation because of the presence of interactions. Duplicate interaction would lower the $\mathrm{F}_{2}$ variance, whereas complementary interaction would increase it. The $F_{2}$ variance is comparatively low, suggesting duplicate interaction.

The segregating generations $\left(F_{2}\right.$ and $\left.B_{2}\right)$ show indication of separation into peaks (Fig. 3). From a single

Table 5 Estimates of the additive, dominance and interaction parameters

\begin{tabular}{lr}
\hline Parameter & \multicolumn{1}{l}{ Estimate } \\
\hline $\mathrm{m}$ & $3.541 \pm 0.284$ \\
{$[\mathrm{~d}]$} & $0.751 \pm 0.066$ \\
{$[\mathrm{~h}]$} & $1.647 \pm 0.749$ \\
{$[\mathrm{i}]$} & $0.612 \pm 0.236$ \\
{$[\mathrm{j}]$} & $-0.149 \pm 1.885$ \\
{$[\mathrm{I}]$} & $-0.147 \pm 4.318$ \\
\hline
\end{tabular}

$\mathrm{m},[\mathrm{d}],[\mathrm{h}]$ and $[\mathrm{i}]$ are significantly larger than their standard error, [j] and [I] are not. locus model with the tolerance trait being dominant, the expectations would be a $1: 3$ and a $1: 1$ NT:T ratio, respectively, in these generations. The $B_{2}$ generation shows two approximately equal peaks, although the means of these appear to be shifted towards the centre as compared to the $P_{1}$ and $P_{2}$ means. The $F_{2}$ generation shows some separation, but a clear $1: 3$ ratio is not apparent. Again, it appears that separate peaks are occurring but that these are shifted towards the centre. Any attempt to calculate significant deviation from 1:3 and $1: 1$ ratios will obviously be entirely dependent on the exact definition of $\mathrm{T}$ and NT. However, for all reasonable estimates of a separating value, the $B_{2}$ data are not significantly different from a $1: 1$ ratio, due to a large gap in the data. No such gap exists in the $F_{2}$ data, but the data are not inconsistent with a 1:3 ratio.

\section{Discussion}

Arsenic tolerance is, therefore, clearly an inherited characteristic. Experiment 1 shows significant heterogeneity in the T:NT ratio. Experiment 2 demonstrates significant additive and dominance components of genetic variation. However, it is not so clear whether, beyond tolerance per se, the genetic architecture of the character allows for any residual variation among tolerant plants. This depends on the dominance relationship and the number of genes.

Experiment 2 shows tolerance to be fully dominant, at least in the cross examined, suggesting that variation in degree of tolerance could not be achieved by dominance effects alone, e.g. by the existence of heterozygotes of intermediate tolerance.

The T:NT ratios of the twenty natural seed families certainly fit with those expected from a single gene with two alleles, the tolerant trait being dominant. Assuming all mine plants to be showing the tolerant trait, (i.e. homozygous tolerant or heterozygous), the offspring families would contain either (a) 100 per cent $T$ plants or (b) a T:NT ratio of 1:1 or greater (depending on the pollen rain), respectively. The data are consistent with 
Table 6 Cavalli joint scaling test using additive, dominance and i-type interaction parameters

\begin{tabular}{lllll}
\hline Parameter & Estimate & Generation & $\begin{array}{l}\text { Observed } \\
\text { mean }\end{array}$ & $\begin{array}{l}\text { Expected } \\
\text { mean }\end{array}$ \\
\hline $\mathrm{m}$ & $3.616 \pm 0.105$ & $\mathrm{P}_{1}$ & 4.90 & 4.89 \\
{$[\mathrm{~d}]$} & $0.731 \pm 0.055$ & $\mathrm{P}_{2}$ & 3.40 & 3.43 \\
{$[\mathrm{~h}]$} & $1.425 \pm 0.144$ & $\mathrm{~F}_{1}$ & 5.04 & 5.04 \\
{$[\mathrm{i}]$} & $0.543 \pm 0.125$ & $\mathrm{~F}_{2}$ & 4.33 & 4.33 \\
& & $\mathrm{~B}_{1}$ & 4.82 & 4.83 \\
$\chi_{[2]}^{2} 0.37$ & & $\mathrm{~B}_{2}$ & 4.14 & 4.10 \\
$P>0.05$ & & & & \\
\hline
\end{tabular}

this pattern. There is some evidence in Experiment 1, however, of heritable variation among the tolerant offspring from families producing all tolerant offspring. In the past, criticism has been levelled at the use of this type of experiment for detecting heritable variation, because the variation could also be caused by either variation in the pollen rain if dominance is not complete, or variation in control root length. However, Experiment 2 indicates complete dominance of arsenic tolerance in this species and control root length variation is not involved in the calculations in this work. Thus, any variation must be assumed to be caused by modifier genes.

The presence of a significant interaction term in Experiment 2 suggests that at least two gene loci must be involved for there to be interaction occurring between them. However, it is possible that this interaction term is an artefact produced by a combination of the crossing programme (as this involved plants from different populations) and the testing method, which relied on a growth parameter. Breaking down coadapted gene complexes which affect a character like growth rate could easily lead to apparent i-type interactions.

No general picture of the numbers of loci involved in heavy-metal tolerance has yet emerged from the genetic studies reported in the literature. In most cases, the results of these studies cannot be adequately explained by postulating a single locus with two alleles, but Wilkins (1960), Urquhart (1971) and Lefébvre (1974), all suggest control by a relatively small number of genes. On the other hand, Jowett (1959), McNeilly (1965), Antonovics (1966) and Gartside and McNeilly (1974a and b) have found continuous variation in metal tolerance, no segregation into classes being apparent. Macnair (1981, 1990) points out that this lack of segregation may be an artefact caused by the inaccuracies involved in measuring tolerance.
It has proved possible to find a discriminating dose for Mimulus guttatus (Macnair, 1983), which permits classification of individuals as T and NT, allowing him to demonstrate control of copper tolerance by a single gene in this species. This does not appear to be achievable in grass species with the exception of arsenic tolerance in A. capillaris (see Fig. 1) and Holcus lanatus (M. R. Macnair, unpublished results).

Attempting to improve the individual accuracy of testing, by examining a much greater number of tillers, would be cumbersome and unrealistic. The alternative is to examine a very large number of individuals in segregating families to see if separate peaks begin to appear in histograms of degree of tolerance. With truly polygenic control, no differentiation into classes would occur. Published work sheds little light on this aspect as the numbers of individuals tested in segregating families (about 20-30) have been too low to be conclusive (Macnair, 1979; Humphreys \& Nicholls, 1984).

The segregating generations of Experiment 2 contain sufficient individuals to detect some differentiation into classes. While the segregation is not complete, nor exactly that predicted by a single gene locus model with the tolerant trait being dominant, separate classes are apparent. These data are consistent with a fairly simple Mendelian model, therefore, and it is not necessary to invoke a more complex genetic model. The classes show a closer approximation to the predictions of a single locus model than to those of a two or three loci model. The simplest explanation of the shape of these histograms is that a single major gene predominates in controlling tolerance and that one or more minor genes of smaller effect modify this control, the shifting of separate peaks towards each other being caused by duplicate interaction between the major and the minor genes. To distinguish unequivocally between polygenic and simple Mendelian control would require further and extensive progeny testing. 


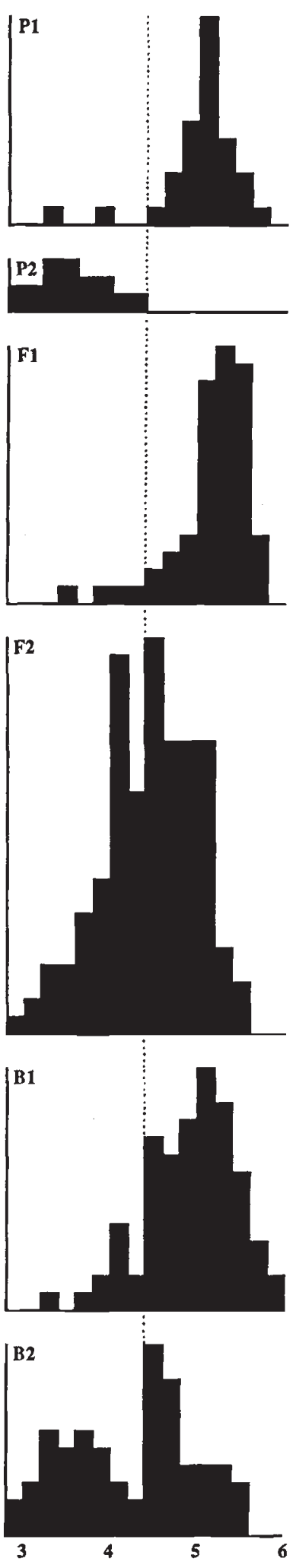

Rep. 1 plant

Fig. 3 Distribution of tolerance values of six generations grown on toxic soil (measured as the cube root of tiller height in $\mathrm{mm}$ ). Class size has been increased for the $\mathrm{P}_{2}$ histogram because of the low number of individuals.
A single gene model with full dominance of the tolerant trait would not allow for a heritable variation in degree of tolerance. However, such variation could exist in a population that contained modifying genes. Selection acting on these genes might result in adaptation to different levels of soil toxicity within a mine.

\section{Conclusion}

Arsenic tolerance is a heritable character in A. capillaris, the tolerant trait being dominant to the non-tolerant trait. The evidence suggests that there is more than one gene locus involved, but that the number of loci is small. The data is best explained by postulating a single major gene for tolerance and one or more minor modifying gene(s) that exhibit(s) duplicate interaction with the major gene. The modifying gene(s) would allow for a heritable variation in degree of tolerance among tolerant plants.

\section{Acknowledgements}

We gratefully acknowledge the support of the N.E.R.C. during this work. Thanks are also due to P. Goodson for help with the care of the plants, Dr J. B. Wilson for the curve fitting technique, Drs W. Kenchington and J. B. Wilson for critically reading the manuscript and an anonymous referee for pointing out an important omission.

\section{References}

Antonovics, J. 1966. Ph.D. Thesis, University of Wales. ANTONOVICS, J., BRADSHAW, A. D. AND TURNER, R. G. 1971. Heavy metal tolerance in plants. Adv. Ecol. Res., 7, 1-85.

CAVALLI, L. L. 1952. An analysis of linkage in quantitative inheritance. In Reeve, E. C. R. and Waddington, C. H. (ed.) Quantitative Inheritance, HMSO, London, pp. 135-144.

GARTSIDE, D. W. AND MCNEILLY, T. 1974a. Genetic studies in heavy metal tolerant plants. I. Genetics of zinc tolerance. Heredity, 32, 287-297.

GARTSIDE, D. W. AND MCNEILLY, T. 1974b. Genetic studies in heavy metal tolerant plants. II. Zinc tolerance in Agrostis tenuis. Heredity, 33, 303-308.

HUMPHREYS, M. O. AND NICHOLLS, M. K. 1984. Relationships between tolerance to heavy metals in Agrostis capillaris L. (Agrostis tenuis Sibth.) New Phytol., 98, 177-190.

IINKS, J. L. AND JONES, R. M. 1958. Estimation of the components of heterosis. Genetics, 43, 223-234.

JOWETT, D. 1959. Ph.D. Thesis, University of Wales.

LEFÉBVRE, C. 1974. Note sur la genetique de la tolerance au zinc chez Armeria maritima (Mill.) Willd. Bull. Soc. Roy. Bot. Belg., 107, 217-222.

MACNAIR, M. R. 1979. The genetics of copper tolerance in the yellow monkey flower, Mimulus guttatus. I. Crosses to nontolerants. Genetics, 91, 553-563. 
MACNAIR, M. R. 1981. Tolerance of higher plants to toxic materials. In Bishop, J. M. and Cook, L. M. (ed.) Genetic Consequences of Man-Made Change, Academic Press, London, pp. 177-208.

MACNAIR, M. R. 1983. The genetic control of copper tolerance in the yellow monkey flower, Mimulus guttatus. Heredity, 50, 283-293.

MACNAIR, M. R. 1987a. Heavy metal tolerance in plants: A model evolutionary system. Trends in Evolution and Ecology, 2, 354-359.

MACNAIR, M. R. 1987b. Metal tolerance on mines in Devon: a natural evolutionary experiment. Nature in Devon, 8 , 29-44.

MACNAIR, M. R. 1990. The genetics of metal tolerance in natural populations. In Shaw, J. (ed.) Heavy metal tolerance in plants: evolutionary aspects. CRC Press, pp. 235-253.

MATHER, K. AND Jinks, J. L. 1971. Biometrical Genetics. Chapman and Hall Ltd., London.

MCNEILLY, T. s. 1965. Ph.D. Thesis, University of Wales.

MCNEILLY, T. S. 1968. Evolution in closely adjacent plant populations. III. Agrostis tenuis on a small copper mine. Heredity, 23, 99-108.

PORTER, E. K. AND PETERSON, P. J. 1977. Arsenic tolerance in grasses growing on mine waste. Environ. Pollut., 14, 255-265.

ROCOVICH, S. E. AND WEST, D. A. 1975. Arsenic tolerance in a population of the grass Andropogon scoparius Michx. Science, 188, 263-264.

URQuHART, c. 1971. Genetics of lead tolerance in Festuca ovina. Heredity, 26, 19-33.

WALLEY, K. A., KHAN, M. S. I. AND BRADShaw, A. D. 1974. The potential for evolution of heavy metal tolerance in plants. I. Copper and zinc tolerance in Agrostis tenuis. Heredity, 32, 309-319.

WILkINS, D. A. 1960. The measurement and genetical analysis of lead tolerance in Festuca ovina. Rep. Scott. P1. Breed. Stn., 85-98.

WILkINS, D. A. 1978. The measurement of tolerance to edaphic factors by means of root growth. New Phytol. 80, 623-633. 